Acta vet. scand. $1986,27,71-79$.

From the Department of Food and Environmental Hygiene, College of Veterinary Medicine, the National Veterinary Institute, Helsinki, and Orion Diagnostica, Espoo, Finland.

\title{
RAPID IMMUNOASSAY FOR DETECTION OF CRYPTOSPORIDIUM OOCYSTS
}

\author{
By \\ Suvi Pohjola, Erkki Neuvonen, Aimo Niskanen and \\ Annikka Rantama
}

POHJOLA, SUVI, ERKKI NEUVONEN, AIMO NISKANEN and ANNIKKA RANTAMA: Rapid immunoassay for detection of Cryptosporidium oocysts. Acta vet. scand. 1986, 27, 71-79. - A direct immunological method by means of latex agglutination (LX) reaction was applied to the demonstration of Cryptosporidium oocysts from stools and gut homogenates. The LX method gave a positive diagnosis for all the specimens judged positive by the modified Ziehl-Neelsen technique, which served as a reference method. The results of the study indicate that the LX method can be adopted as a diagnostic tool for cryptosporidiosis, but further study concerning the specificity and sensitivity of the method is clearly warranted.

faecal samples; i m munodiagnosis; latexag glutination.

Since the first report of human cryptosporidiosis by Nime in 1976, followed by the early literature of sporadic infection in immunocompromised persons (Meisel et al. 1976, Lasser et al. 1979, Weisburger et al. 1979, Stemmermann et al. 1980, Weinstein et al. 1981, Sloper et al. 1982, Center for Disease Control 1982, Miller et al. 1983), recent research has revealed cryptosporidiosis world-wide also in immunocomptent individuals (Tzipori et al. 1980, Anderson et al. 1982, Reese et al. 1982) and even in larger populations (Jokipii et al. 1983, Tzipori et al. 1983, Bogaerts et al. 1984, Hunt et al. 1984, Mata et al. 1984, Jokipii et al. 1985).

Cryptosporidiosis, important as a human disease, is also of agricultural economic signifilcance, since the infection may affect up to $95 \%$ of calves under the age of 1 month (Stein et al.1983). It is usually neonatal and young calves, which show clinical 
symptoms of enteritis (Krogh \& Henriksen 1985), whereas older calves may have asymptomatic infections (Pohjola et al. 1986).

Outbreaks of human cryptosporidiosis with zoonotic implications of bovine origin have been described (Anderson et al. 1982, Reese et al. 1982, Rahaman et al. 1984, Pohjola et al. in print). The concept of cryptosporidiosis as an emerging zoonosis, and the importance of the organisms as a prevalent but overlooked cause of diarrhea among humans in agricultural occupations, particularly in less developed countries, has been suggested (Schultz 1983). Recently we have demonstrated that Cryptosporidium in a rural population is asymptomatic and occurs mainly in persons in close contact with cattle (author's unpublished data).

Cryptosporidium is distinct from other enteric coccidila in not exhibiting much host or site specificity. The parasite's life cycle is direct and rapid and occurs on the microvillous borders of the enterocytes. Endogenous stages have occasionally also been detected on other epithelial surfaces, particularly in the respiratory and biliary tracts and in the gall bladder. The infection is transmitted by ingestion of endogenously sporulated oocysts, excreted in the faeces (Tzipori 1983).

A diagnosis of cryptosporidiosis may be based on observation of the endogenous stages of the organisms in intestinal mucosa obtained by biopsy or necropsy (Nime et al. 1976, Lasser et al. 1979, Weisburger et al. 1979, Stemmermann et al. 1980, Weinstein et al. 1981) or on demonstration of oocysts in faeces, either from direct smears (Tzipori et al. 1980, Tzipori et al. 1983, Bogaerts et al. 1984, Hunt et al. 1984, Mata et al. 1984) or from faecal concentrates (Anderson et al. 1982, Reese et al. 1982, Jokipii et al. 1983, Bogaerts et al. 1984, Jokipii et al. 1985). In this paper we describe the initial results of a latex of a agglutination (LX) method, recently evaluated in rotavirus antigen detection (Haikala et al. 1983, Hughes et al. 1984), in the demonstration of oocysts of Cryptosporidium from stools and gut homogenates from experimentally infected calves and mice.

\section{MATERIALS AND METHODS}

Antigen preparation

Oocysts of Cryptosporidium used as antigens had been passaged through 5 litters of $1-4$ days old offspring of Han-NMRI 
specific-pathogen-free (SPF) mice (Orion Diagnostica, Espoo, Finland) before one passage in a newborn calf. Oocysts were harvested by filtration through a sieve with mesh of $60 \mathrm{~nm}$ and their morphology was checked from the smeared sediment stained with the modified Ziehl-Neelsen method (Henriksen \& Pohlenz 1981). The faecal suspension was mixed with an equal amount of absolute ethanol, held at $+4^{\circ} \mathrm{C}$ for $1 \mathrm{~h}$, and then centrifuged at $400 \mathrm{~g}$ at $4^{\circ} \mathrm{C}$ for $30 \mathrm{~min}$. The collected sediment phase was diluted with the original volume of Hank's saline, and similarly centrifuged for the second time as resuspended to the original volume of Hank's saline. The absence of bacterial contamination was checked by culturing on $5 \%$ bovine blood agar before emulsifying with an equal mount of Freund complete adjuvant.

\section{Antiserum preparation}

A male albino rabbit was subcutaneously injected with $2 \mathrm{ml}$ of a oocyst-adjuvant mixture. The animal received a booster immunization 4 times fortnightly with an equal dose, and 10 days after the fourth injection it was exsanguinated.

The sensitization of the latex particles was performed according to the methods described previously (Haikala et al. 1983). The sensitized reagent solutions, with dilutions of $1: 20$ and 1:40 of the sera, as well as the negative control solution (nonimmunized rabbit sera coated with latex particles) were stored at $4^{\circ} \mathrm{C}$.

\section{Latex agglutination test}

Watery stool specimens were obtained from 6 diarrheic, experimentally infected calves, all under the age of 2 weeks. Faecal specimens from 2 uninfected, but diarrheic calves served as negative controls.

Gut homogenates were collected from thirty-two 3 to 15 days old mice. 20 mice had been infected when newborn with oocysts of Cryptosporidium and $\mathbf{1 2}$ mice left as uninfected controls.

For the latex agglutination test, each faecal specimen from the calves was placed in a disposable plastic container with a screen with $60 \mathrm{~nm}$ holes. After thorough mixing the cap was removed and a drop of faecal fluid was siphoned off onto a black tile (adopted from the Latex agglutination test kit) and mixed with a drop of the LX-reagent or the negative control reagent. 
Each mixed specimen of bovine origin was tilted on the tile for 2 min before evaluation of the reaction under an illuminating magnifying glass, a magnification of $3 \mathrm{x}$. The $\mathrm{LX}$ test was considered to be positive if agglutination was observed, provided that the negative control test remained milky. Unfiltrated gut homogenates from mice were transferred with disposable culture loops onto a black tile, otherwise the test was carried out in the manner described above.

\section{Light microscopy}

To obtain a reference to the immunological method, each bovine faecal specimen and murine gut homogenate was smeared on the microscope slides, air-dried, fixed in absolute methanol and stained with the modified Ziehl-Neelsen staining technique (Henriksen \& Pohlenz 1981) as described previously (Jokipii et al. 1983). The stained slides were examined under oil-immersion at a magnification of $1000 \times$.

\section{RESULTS}

Observations obtained from the faecal specimens and gut homogenates by the LX method are presented in Table 1. For the sake of comparison, Table 1 also gives results obtained from the same specimens after staining with the modified Ziehl-Neelsen technique.

Acid-fast oocysts were observed in all the specimens taken from experimentally infected animals, whereas specimens from control animals were negative for Cryptosporidium oocysts.

T a b l e 1. Latex-agglutination (LX) test and modified Ziehl-Neelsen staining technique in detection of Cryptosporidium oocysts from bovine stool specimen and murine gut homogenates.

\begin{tabular}{|c|c|c|c|c|c|}
\hline & \multirow{2}{*}{$\begin{array}{l}\text { Number of } \\
\text { specimen }\end{array}$} & \multicolumn{3}{|c|}{ LX reactions with } & \multirow{2}{*}{$\begin{array}{l}\text { ZN-staining } \\
\text { reaction }\end{array}$} \\
\hline & & $\begin{array}{l}\text { dilut } \\
1: 20\end{array}$ & $\begin{array}{l}\text { atisera } \\
1: 40\end{array}$ & $\begin{array}{l}\text { negative } \\
\text { control }\end{array}$ & \\
\hline Calves & $\begin{array}{l}6 \\
2 \\
\end{array}$ & + & + & - & + \\
\hline Mice & $\begin{array}{r}13 \\
7 \\
11 \\
1\end{array}$ & $\begin{array}{l}+ \\
+ \\
-\end{array}$ & $\begin{array}{l}+ \\
+ \\
-\end{array}$ & $\frac{-}{+}$ & $\begin{array}{l}+ \\
+ \\
-\end{array}$ \\
\hline
\end{tabular}


A latex agglutination reaction was recorded with both dilutions of antisera in all the specimens defined as positive by the modified Ziehl-Neelsen technique. However, 7 gut homogenates taken from experimentally infected mice and 1 from an uninfected control mouse also gave a positive reaction with the control antisera.

The $L X$ reaction proved to be difficult to interpret in a few of the murine gut homogenates apparently due to the large amounts of cells and luminal debris. When the tilting time was extended over $3 \mathrm{~min}$, the agglutination reaction was observed in some other specimens from uninfected control animals, apparently because of nonspecific reactions.

\section{DISCUSSION}

In recent years several methods have been used for the diagnosis of cryptosporidiosis; most of the diagnostic methods used until now require advanced research facilities with experienced personnel. The early methods used in human cases were lightor electron microscopy of an intestinal biopsy specimen (Meisel et al. 1976, Lasser et al. 1979, Weisburger et al. 1979, Stemmerman et al. 1980, Weinstein et al. 1981, Sloper et al. 1982). The existence of oocysts and thus the basis for examination of stools was demonstrated already in 1978 in studies of neonatal calf diarrhea by Pohlenz et al.

Oocysts can be demonstrated in smears stained with various techniques; those most frequently applied are the Giemsa (Tzipori et al. 1980, Anderson et al. 1982, Reese et al. 1982), the modified Ziehl-Neelsen (Bogaerts et al. 1984, Hunt et al. 1984) and the safranin-methylene blue (Bogaerts et al. 1984, Baxby et al. 1984). To improve the detection of the oocysts, faecal samples have been concentrated with various procedures; among the most frequently used are the formalin-ether sedimentation method (Jokipii et al. 1983, Bogaerts et al. 1984) and faecal flotation using Sheather's sucrose solution (Anderson et al. 1982, Bennet et al. 1985).

Rapid staining methods include the negative staining methods using carbol-fuchsin (Stein et al. 1983) and nigrosin (Pohjola 1983) or DMSO-modified Ziehl-Neelsen staining technique (Bronsdon 1984, Pohjola et al. 1984). 
An indirect serological method of diagnosis by means of indirect immunofluorescence (IIF) has been used in demonstration of antibodies to Cryptosporidium in humans and animals (Tzipori \& Campbell 1981, Campbell \& Current 1983). However, the seroconversions detected reflect previous exposure, even 360 - 400 days earlier (Campbell \& Current 1983), and hence do not necessarily bear any diagnostic value at the time of the test.

Direct and rapid immunodiagnosis of cryptosporidiosis by means of latex agglutination is based on the presence of oocysts in stools during the acute phase of the infection. The initial observations of this macroscopical detection method were promising. The test appeared to be rapid an easy to perform, and did not need expensive equipment. All the specimens with acid fast oosysts judged by the the modified Ziehl-Neelsen staining technique gave positive latex agglutination reaction. However, nonspecified LX reactions was observed in some specimens of mice, apparently because sera of the nonimmunized rabbit had antibodies against some organisms of murine gut contents.

The prevention and control of the ubiquitous, zoonotic and potentially pathogenic Cryptosporidium demands simple and safe tests for both medical and veterinary clinicians and researchers. Further studies are being carried out with several species of animals to provide information on the sensitivity and specificity and the optimal test conditions of the LX test for Cryptosporidium.

\section{REFERENCES}

Anderson, B. C., T. Donndelinger, R. M. Wilkins \& J. Smith: Cryptosporidiosis in a veterinary student. J. Amer. vet. med. Assoc. 1982, 180, 408-409.

Baxby, D., N. Blundell \& D. Hart: The development and performance of a simple sensitive method for the detection of Cryptosporidium oocysts in feces. J. Hyg. (Camb.) 1984, 92, 317-323.

Bennet, M., D. Baxby, N. Blundell, C. J. Gaskell, C. A. Hart \& D. F. Kelly: Cryptosporidiosis in a domestic cat. Vet. Rec. 1985, 116, 73-74.

Bogaerts, J., P. Lepage, D. Rouvroy \& J. Vandepitte: Cryptosporidium spp., a frequent cause of diarrhea in central Africa. J. clin. Microbiol. 1984, 20, 874-876.

Bronsdon, M. A.: Rapid dimethyl sulfoxide - modified acid fast satin of Cryptosporidium oocysts in stool specimen. J. clin. Microbiol. 1984, 19, 952-953. 
Campbell, P. N.\&W. L. Current: Demonstration of serum antibodies to Cryptosporidium sp. in normal and immunodeficient humans with confirmed infections. J. clin. Microbiol. 1983, 18, 165-169.

Center for Disease Control: Cryptosporidiosis: Assessment of chemotherapy of males with acquired immune deficiency syndrome (AIDS). MMWR 1982, 31, 589-592.

Haikala, O. J., J. O. Kokkonen, M. K. Leinonen, T. Nurmi, R. Mäntyjärvi \& H. K. Sarkkinen: Rapid detection of rotavirus in stool by Latex agglutination: Comparison with radioimmunoassay and electron microscopy and clinical evaluation of the test. J. med. Virol. 1983, 11, 91-97.

Henriksen, Sv. Aa. \& J. F. Pohlenz: Staining of cryptosporidia by a modified Ziehl-Neelsen technique. Acta vet. scand. 1981, 22, $594-596$.

Hughes, J. H., A. V. Tuomari, D. R. Mann \& V. V. Hamparian: Latex immunoassay for rapid detection of rotavirus. J. clin. Microbiol. 1984, 20, 441-447.

Hunt, D. A., R. Shannon, S. R. Palmer \& A. E. Jephcott: Cryptosporidiosis in an urban community. Brit. med. J. 1984, 289, 814-816.

Jokipii, L., S. Pohjola \& A. M. M. Jokipii: Cryptosporidium: a frequent finding in patients with pastrointestinal symptoms. Lancet 1983, ii, $358-360$.

Jokipii, L., S. Pohjola \& A. M. M. Jokipii: Cryptosporidiosis associated with traveling and giardiasis. Gastroenterology 1985, 89, 838842.

Krogh, H. V. \& Sv. Aa. Henriksen: Bovine Cryptosporidiosis in Denmark. 2. Cryptosporidia associated with neonatal calf diarrhea. Nord. Vet.-Med. 1985, 37, 42-47.

Lasser, K. H., K. J. Lewin \& F. W. Ryning: Cryptosporidial enteritis in a patient with congenital hypogammaglobulinemia. Hum. Pathol. 1979, 10, 234-240.

Mata, L., H. Bolanos, D. Pizarro \& M. Vives: Cryptosporidiosis in children from some highland Costa Rican rural and urban areas. Amer. J. trop. Med. Hyg. 1984, 33, 24-29.

Meisel, J. L., D. R. Perera, C. Meligro \& C. E. Rubin: Overwhelming watery diarrhea associated with cryptosporidium in an immunosuppressed patient. Gastroenterology 1976, 70, 11561160.

Miller, R. A., R. E. Holmberg \& C. R. Clausen: Life-threatening diarrhea caused by Cryptosporidium in a child undergoing therapy for acute lymphocytic leukemia. J. Pediaí. 1983, 103, 256-259.

Nime, F. A., J. D. Burek, D. L. Page, M. A. Holscher \& J. H. H. Yardley: Acute enterocolitis in a human being infected with protozoan Cryptosporidium. Gastroenterology 1976, 70, 592-598.

Pohjola, S.: Negative staining method with nigrosin in detection of cryptosporidial oocysts: a comparative study. Res. Vet. Sci. 1983, 36, 217-219. 
Pohjola., S., L. Jokipii \& A. M. M. Jokipii: Dimethylsulphoxide-ZiehlNeelsen staining technique for detection of cryptosporidial oocysts. Vet. Rec. 1984, 115, 442-443.

Pohjola, S., H. Oksanen, E. Neuvonen, P. Veijalainen \& K. Henriksson: Certain enteropathogens in calves of Finnish dairy herds with recurrent outbreaks of diarrhea. Prev. Vet. Med. 1986, 3, 547558.

Pohjola, S., H. Oksanen, L. Jokipii \& A. M. H. Jokipii: Outbreak of cryptosporidiosis among veterinary students. Scand. J. inf. Dis., in print.

Pohlenz, J., H. W. Moon, N. F. Cheville \& W. J. Bembrick: Cryptosporidiosis as a probable factor in neonatal diarrhea in calves. J. Amer. vet. med. Assoc. 1978, 172, 452-457.

Rahaman, A. S. M. H., S. C. Sanyal, K. A. Al-Mahmud, A. Sobhan K. S. Hossain \& B. C. Anderson: Cryptosporidiosis in calves and their handlers in Bangladesh. Lancet 1984, ii, 221.

Reese, N. C., W. L. Current, J. V. Ernst \& W. S. Bailey: Cryptosporidium in man and calf: a case report and results of experimental infections in mice and rats. Amer. J. trop. Med. Hyg. 1982, 31, 226 -229 .

Schultz, M. G.: Emerging zoonoses. N. Engl. J. Med. 1983, 308, 12851286.

Sloper, K. S., R. R. Dourmashkin, R. B. Bird, G. Slavin \& A. D. B. Webster: Chronic malabsorption due to cryptosporidiosis in a child with immunoglobulin deficiency. Gut 1982, 23, 80-82.

Stein, E., J. Boch, J. Heine \& G. Henkel: Der Verlauf natürlicher Cryptosporidium-Infektionen in vier Rindersucht betrieben. (Course of natural Cryptosporidium infections on 4 cattle-breeding farms). Berl. Münch. tierärztl. Wschr. 1983, 96, 222-225.

Stemmermann, G. N., T. Hyashi, G. A. Glober, N. Oishi \& R. I. Frankel: Cryptosporidiosis, report of a fatal case complicated by disseminated toxoplasmosis. Amer. J. Med. 1980, 69, 637-642.

Tzipori, S. \& I. Campbell: Prevalence of Cryptosporidium antibodies in 10 animal species. J. clin. Microbiol. 1981, 14, 455-456.

Tzipori, S.: Cryptosporidiosis in animals and humans. Microbiol. 1983, 47, 84-96.

Tzipori, S., M. Smith, C. Birch, G. Barnes \& R. Bishop: Cryptosporidiosis in hospital patients with gastroenteritis. Amer. J. trop. Med. Hyg. 1983, 32, 931-934.

Weinstein, L. S. M. Edelstein, J. L. Madara, K. R. Falchuk, B. M. Mc Manus \& J. S. Trier: Intestinal cryptosporidiosis complicated by disseminated cytomegalovirus infection. Gastroenterology 1981, 81, 584-591.

Weisburger, W. R., D. F. Hutcheon, J. H. Yardley, J. C. Roche, W. D. Hillis \& P. Charade: Cryptosporidiosis in an immunosuppressed renal-transplant recipient with IgA deficiency. Amer. clin. Pathol. 1979, 72, 473-478. 


\section{SAMMANDRAG}

En snabb immunmetod för påvisning av Cryptosporidium oocystor.

En direkt immunologisk metod baserad på latex agglutinations (LX) reaktion tillämpades för att påvisa Cryptosporidium oocystor $i$ avföring och tarmhomogenat. LX metoden gav positiv diagnos för alla preparat som också var positiva med modifierad Ziehl-Neelsen teknik, vilken fungerade som referensmetod. Resultaten visar att LX metoden kan användas vid diagnostik av kryptosporidios, men ytterligare studier med avseende på metodens specifitet och sensitivitet är nödvändiga.

\section{(Received December 4, 1985).}

Reprints may be requested from: Suvi Pohjola, the College of Veterinary Medicine, Department of Food and Environmental Hygiene, P. O. Box 6, SF-00551, Helsinki, Finland. 